\title{
Pancreatic fistula after pancreaticoduodenectomy-does surgical technique matter?
}

\author{
Stefano Crippa ${ }^{1,2}$, Massimo Falconi $^{1,2}$ \\ ${ }^{1}$ School of Medicine, Vita-Salute San Raffaele University, Milan, Italy; ${ }^{2}$ Division of Pancreatic Surgery, Pancreas Translational \& Clinical Research \\ Center, IRCCS San Raffaele Scientific Institute, Milan, Italy \\ Correspondence to: Massimo Falconi, MD. Department of Surgery, Division of Pancreatic Surgery, San Raffaele Scientific Institute IRCCS, Università \\ Vita-Salute, Via Olgettina 60, 20132 Milan, Italy. Email: falconi.massimo@hsr.it. \\ Provenance and Peer Review: This article was commissioned by the editorial office, Annals of Translational Medicine. The article did not undergo \\ external peer review. \\ Comment on: Kim SG, Paik KY, Oh JS. The vulnerable point of modified blumgart pancreaticojejunostomy regarding pancreatic fistula learned from \\ 51 consecutive pancreaticoduodenectomy. Ann Transl Med 2019;7:630.
}

Submitted Feb 18, 2020. Accepted for publication Mar 05, 2020.

doi: $10.21037 /$ atm.2020.03.123

View this article at: http://dx.doi.org/10.21037/atm.2020.03.123

Pancreaticoduodenectomy (PD) is the procedure of choice for the treatment of cancers of the pancreatic head and of periampullary region. Indications for PD have increased over time, since PD is performed also for the treatment of well-recognized pre-invasive tumors arising in this anatomical region (i.e., intraductal papillary mucinous neoplasms; IPMN) (1). PD is a complex procedure associated with a significant rate of postoperative morbidity and with a mortality rate around $2-3 \%$ when performed at high-volume referral centers (2). PD-related morbidity is mainly associated with the development of pancreatic fistula after pancreatic anastomosis (3). Pancreatic fistula is in fact the major determinant of several complications after PD including, infections up to severe sepsis, late bleeding from arterial pseudo aneurysm following arterial erosion due to pancreatic juice, intra-abdominal collections and abscesses, delayed gastric emptying, leakage of biliary and/or gastroenteric anastomosis. For all these reasons pancreatic anastomosis has been defined as the "Achilles' heel" of pancreatic surgery. Surgeons dedicated to the pancreas have tried to overcome the issue of pancreatic fistula for many years and with different strategies. These efforts encompass the site of anastomosis (pancreatojejunostomy versus pancreatogastrostomy) and the anastomotic technique (duct-to-mucosa, invagination, dunking, Blumgart pancreatojejunostomy). Moreover some surgical details have been adopted as well such as the number of anastomotic layers (single versus double), the use of a single versus double intestinal loops, the use of internal versus external pancreatic stents, the application of fibrin glue, the administration of drugs to decrease pancreatic secretion (i.e., octreotide and its analogues), type of suture materials used. The number, site and type of drains placed during the operation were studied as well as their removal timing (4-11). However, there are no established strategies that proved to be effective in decreasing the rate of pancreatic fistula, and mainly, of clinically relevant pancreatic fistulaa pancreatic fistula with clinical impact on the postoperative course of the patient.

In this setting, Kim and colleagues (12) reported their experience with 50 consecutive PD with modified Blumgart anastomosis (BA). In their retrospective analysis, they found a $10 \%$ rate of postoperative pancreatic fistula (POPF), including $8 \%$ of grade B and $2 \%$ of grade C POPF. Only one patient died in this cohort, and Authors found a jejunal detachment from the pancreas stump, "because the jejunum was too thin compared with the thickness" of the pancreas. Therefore, they concluded that, irrespectively of modification of the BA (interrupted suture between the pancreatic parenchyma and jejunum) $(12,13)$, the anastomosis between a thin jejunum and a thick pancreas as a risk factor for POPF. Clearly, this study has all the drawbacks of a retrospective analysis, mostly considering the small number of patients analyzed in a very long period (50 cases performed during a 7-year period for a mean of only 7.1 cases/year). It is unclear if a single surgeon 
performed all the procedures and if this was the only anastomotic technique used in the study period, as the risk of selections bias would be very high. The use of anastomotic stent was different case by case and there are no data regarding the administration of somatostatin analogues. Moreover, it is unclear how the texture of the pancreatic gland as well as the size of main pancreatic duct influenced the development of POPF. There are no clear data regarding the postoperative management of the patients considered, and it is unclear if intraoperative/ postoperative techniques and strategies changed over time. Finally, it is impossible to draw conclusions regarding a specific anastomotic technique by evaluating the fate of a single case. Although we agree that retrospective studies can give insights into some issues, the scientific applicability of the results of this study is minimal.

This allows us to make some final considerations. Firstly, surgeons focused their attention of specific technical issues to solve the unsolved problem of pancreatic fistula. However, the most important risk factor for pancreatic fistula is the pancreas itself (i.e., soft pancreas with small main pancreatic duct) (14), and therefore studies should be focused on mitigation strategies in order to decrease the clinical impact of POF rather than to prevent it. Secondly, in order to achieve this mitigation strategy, it is of paramount importance the experience of the surgeon and even more relevant, of the center where pancreatic surgery is performed $(15,16)$. This is particularly true for postoperative mortality. In fact, a linear correlation between surgeon/hospital volume and mortality has been largely demonstrated. Finally yet importantly, there is a methodological problem. Retrospective, single center, maybe single surgeon, studies have too many drawbacks, but also randomized controlled trials (RCT) may have significant limitations. In a systematic review and metaanalysis of randomized controlled trials (RCT) comparing pancreatojejunostomy (PJ) and pancreatogastrostomy (PG) we analyzed ten RCTs including 1,629 patients (10). The most relevant results of this work was the evidence of a significant heterogeneity regarding the definitions of POPF, anastomotic techniques, perioperative management, and the characteristics of pancreatic gland among the different trials. We found that that PG and PJ were comparable in term of overall and clinically significant POPF, overall morbidity, reoperations, and mortality.

In order to appropriately assess benefits and pitfalls of an anastomotic technique in the setting of pancreatoduodenectomy, only well-planned and powered
RCT should be considered. These studies should be mainly focused to high-risk patients (i.e., patients with soft pancreas) and they should include standardized and homogeneous techniques, standardized and universally accepted definitions of POPF/complications as well as standardized perioperative/postoperative management. The experience of participating surgeons and hospitals should be also considered in order to avoid bias related to poor experience of operating surgeons of to a low hospital volume. In this setting, the cooperation among high-volume referral centers will be indispensable.

\section{Acknowledgments}

Funding: None.

\section{Footnote}

Conflicts of Interest: Both authors have completed the ICMJE uniform disclosure form (available at http://dx.doi. org/10.21037/atm.2020.03.123). The authors have no conflicts of interest to declare.

Ethical Statement: The authors are accountable for all aspects of the work in ensuring that questions related to the accuracy or integrity of any part of the work are appropriately investigated and resolved.

Open Access Statement: This is an Open Access article distributed in accordance with the Creative Commons Attribution-NonCommercial-NoDerivs 4.0 International License (CC BY-NC-ND 4.0), which permits the noncommercial replication and distribution of the article with the strict proviso that no changes or edits are made and the original work is properly cited (including links to both the formal publication through the relevant DOI and the license). See: https://creativecommons.org/licenses/by-nc-nd/4.0/.

\section{References}

1. van Huijgevoort NCM, Del Chiaro M, Wolfgang CL, et al. Diagnosis and management of pancreatic cystic neoplasms: current evidence and guidelines. Nat Rev Gastroenterol Hepatol 2019;16:676-89.

2. Marchegiani G, Andrianello S, Salvia R, et al. Current Definition of and Controversial Issues Regarding Postoperative Pancreatic Fistulas. Gut Liver 2019;13:149-53.

3. Crippa S, Salvia R, Falconi M, et al. Anastomotic leakage 
in pancreatic surgery. HPB (Oxford) 2007;9:8-15.

4. Li T, D'Cruz RT, Lim SY, et al. Somatostatin analogues and the risk of post-operative pancreatic fistulas after pancreatic resection - A systematic review \& meta-analysis. Pancreatology 2019. [Epub ahead of print].

5. Kamarajah SK, Bundred JR, Marc OS, et al. A systematic review and network meta-analysis of different surgical approaches for pancreaticoduodenectomy. HPB (Oxford) 2019. [Epub ahead of print].

6. Schorn S, Demir IE, Vogel T, et al. Mortality and postoperative complications after different types of surgical reconstruction following pancreaticoduodenectomy-a systematic review with meta-analysis. Langenbecks Arch Surg 2019;404:141-57.

7. Adiamah A, Arif Z, Berti F, et al. The Use of Prophylactic Somatostatin Therapy Following Pancreaticoduodenectomy: A Meta-analysis of Randomised Controlled Trials. World J Surg 2019;43:1788-801.

8. Wang C, Zhao X, You S. Efficacy of the prophylactic use of octreotide for the prevention of complications after pancreatic resection: An updated systematic review and meta-analysis of randomized controlled trials. Medicine (Baltimore) 2017;96:e7500.

9. Dong Z, Xu J, Wang Z, et al. Stents for the prevention of pancreatic fistula following pancreaticoduodenectomy. Cochrane Database Syst Rev 2016;(5):CD008914.

10. Crippa S, Cirocchi R, Randolph J, et al.

Cite this article as: Crippa S, Falconi M. Pancreatic fistula after pancreaticoduodenectomy-does surgical technique matter? Ann Transl Med 2020;8(11):669. doi: 10.21037/ atm.2020.03.123
Pancreaticojejunostomy is comparable to pancreaticogastrostomy after pancreaticoduodenectomy: an updated meta-analysis of randomized controlled trials. Langenbecks Arch Sur 2016;401:427-37.

11. Kim SG, Paik KY, Oh JS. The vulnerable point of modified blumgart pancreaticojejunostomy regarding pancreatic fistula learned from 50 consecutive pancreaticoduodenectomy. Ann Transl Med 2019;7:630.

12. Kleespies A, Rentsch M, Seeliger H, et al. Blumgart anastomosis for pancreaticojejunostomy minimizes severe complications after pancreatic head resection. Br J Surg 2009;96:741-50.

13. Fujii T, Sugimoto H, Yamada S, et al. Modified blumgart anastomosis for pancreaticojejunostomy: technical improvement in matched historical control study. J Gastrointest Surg 2014;18:1108-15.

14. Callery MP, Pratt WB, Kent TS, et al. A prospectively validated clinical risk score accurately predicts pancreatic fistula after pancreatoduodenectomy. J Am Coll Surg 2013;216:1-14.

15. Balzano G, Capretti G, Callea G, et al. Overuse of surgery in patients with pancreatic cancer. A nationwide analysis in Italy. HPB (Oxford) 2016;18:470-8.

16. Birkmeyer JD, Stukel TA, Siewers AE, et al. Surgeon volume and operative mortality in the United States. N Engl J Med 2003;349:2117-27. 